\title{
Power Density Maximization in Medium Frequency Transformers by Using Their Maximum Flux Density for DC-DC Converters
}

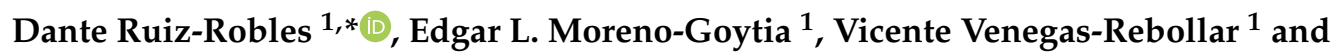 \\ Nadia M. Salgado-Herrera ${ }^{2}$ (D) \\ 1 Graduate Program and Research in Electrical Engineering (PGIIE), Tecnológico Nacional de México/Instituto \\ Tecnológico de Morelia, Morelia 58120, Mexico; elmoreno@itmorelia.edu.mx (E.L.M.-G.); \\ vvenegasr@itmorelia.edu.mx (V.V.-R.) \\ 2 Instituto de Energías Renovables, Universidad Nacional Autónoma de México: Priv. Xochicalco S/N, \\ Temixco 62580, Morelos, Mexico; nasahe@ier.unam.mx \\ * Correspondence: Dante@tecmor.mx; Tel.: +52-443-221-3177
}

Received: 15 February 2020; Accepted: 8 March 2020; Published: 11 March 2020

\begin{abstract}
The medium frequency transformer (MTF) is a key component of various new DC-DC converters that are designed for applications in modern electrical power grids at medium and high voltage. To attain the high performance that are necessary for targeting these applications, MFTs should have high power density and high efficiency as characteristics. For this endeavor, newly designed MFT procedures, which also take advantages of new core materials, are under investigation. Differently to other design proposals, most of which use conventional transformer design procedures based on equating core losses to copper conduction losses, in this paper, an MTF with a nanocrystalline (VITROPERM 500F) core is designed with a new procedure that is oriented in aiming the maximum flux density $\left(B_{\max }\right)$. The characteristics of the MFTs that are obtained by using this procedure are compared with those of the MFTFs that are designed with a conventional procedure. The results show that by using the proposed technique, we get a $25 \%$ reduction in the winding size, a higher power density, and a lower MTF building cost while maintaining a high efficiency $(>98 \%)$. The design methodology is developed through a rigorous mathematical analysis that is verified with computer simulations in Matlab-Simulink and validated with experimental results from two MTF laboratory prototypes designed at a flux density of $0.9 \mathrm{~T}\left(75 \% B_{\max }\right)$ and $1.2 \mathrm{~T}\left(B_{\max }\right)$.
\end{abstract}

Keywords: converter DC-DC; electric vehicles; renewable energies; solid state transformers

\section{Introduction}

One of the leading research goals regarding high or medium frequency transformers is the increase power density while maintaining a high efficiency (98\%) [1-6]. These characteristics open many opportunities to these transformers in a wide range of applications in electrical distribution grids [1,7-9]. In this paper, we report our research efforts on designing medium frequency transformers (MTFs) from a different point of view than the conventional ones. The MFT is fundamental in the development of new DC-DC converters that operate as part of a) photovoltaic systems [2], b) wind power systems [3], c) solid-state transformers [10], d) electric vehicles [11], e) diesel generators [12,13], and f) smart grid interfaces. It is worth mentioning that a high-power density that is maintained at a reasonably high efficiency is desired in DC-DC converters, as well as in MTFs.

In order to design MTFs at a medium-voltage range, several materials have been studied and analyzed. Among all of them, nanocrystalline-alloys have shown great potential [4]. Nanocrystalline materials exhibit desirable features at a medium-frequency range that allow MFTs to get higher power 
density and efficiency values than with other materials such as silicon steel, ferrites, and different amorphous materials [10]. The nanocrystalline materials combine the advantageous properties of soft magnetic materials, such as a high magnetic saturation [14], with their own properties. These properties are preserved even at higher frequencies and temperatures $[15,16]$. Therefore, nanocrystalline magnetic cores are greatly suitable for designing medium voltage, medium frequency transformers. However, the design of transformers with this type of core is not straightforward, and more research on design procedures is needed [17]. Improved nanocrystalline magnetic core designs also have opportunities in various other applications $[18,19]$.

The flux density $\left(B_{a c}\right)$ that was reported in [5] for MTFs that were designed with nanocrystalline cores is $75 \%(0.9 \mathrm{~T})$ of its maximum density flux, $B_{\max }=1.2 \mathrm{~T}$. For other core materials, e.g., a silicon steel, the design of transformers at the medium-frequency range is carried out at $B_{a c}=0.5 \mathrm{~T}$ and $1 \mathrm{kHz}[6]$ because if the maximum flux density is reached $\left(B_{\max }\right)$, then the core losses will increase and result in an efficiency reduction below the minimum required reduction of $98 \%$. However, if the operating frequency for silicon steel core MTFs is reduced to $600 \mathrm{~Hz}$, as required by the design, then $B_{a c}$ will increase to $0.6 \mathrm{~T}$ [3]. In this case, such a value of $B_{a c}$ is far below the $B_{\max }$ value that can be obtained with nanocrystalline materials. It is worth mentioning that in a design, the higher the needed MTF power density, the higher the required flux density $\left(B_{a c}\right)$.

The usual value of $B_{a c}$ for amorphous materials in MTFs operating at $3.6 \mathrm{kHz}$ is $0.5 \mathrm{~T}$ [20]. Using higher flux density in these materials results in higher core losses and lower transformer efficiency. Moreover, core losses at $B_{a c}=1.2 \mathrm{~T}$ and $5 \mathrm{kHz}$ are lower for nanocrystalline $\left(B_{\max }=1.2 \mathrm{~T}\right)$ than for amorphous materials $\left(B_{\max }=1.5 \mathrm{~T}\right)$ [20]. Other materials for MTFs cores, such as ferrites, are in use for frequencies greater than $20 \mathrm{kHz}$ at $B_{a c}=0.35 \mathrm{~T}$ [20]. This value of $B_{a c}$ is far lower than the one obtained with nanocrystalline materials $(0.9 \mathrm{~T})$ [2].

It must be stressed that previous research efforts have overlooked the opportunity to design nanocrystalline cores for MFT-based DC-DC converters with a maximum flux density under certain conditions. Besides this latter consideration, it is also possible to get a reduction in the number of winding turns of the MTF and a higher power density while maintaining a high efficiency $(98 \%)$ by using a new design procedure. DC-DC converters, with a boosted power density characteristic, can be applied to a) the interconnection of photovoltaic systems, b) electric vehicles, c) solid-state transformers, and 4) built-in wind generators. The classical design theory of conventional transformers [21] states than an optimal design is achieved once the core losses are equal to the copper conductor losses. By taking into consideration the idea that core losses for nanocrystalline materials are much lower than copper conduction losses, we can learn that such classical theory cannot be applied to nanocrystalline materials. Therefore, further research efforts are required to determine the conditions for which power density can be increased while maintaining a high efficiency in nanocrystalline cores. This point is addressed in the present paper.

\section{Contributions From This Work.}

The main contribution of this paper is the introduction of a novel design procedure that gives MFT designers a cutting-edge tool for designing efficient MFTs for DC-DC converters at a maximum flux density. These converters have a niche of opportunity in building smart grid environments.

To assess the effectiveness of this proposal, two MFTs with nanocrystalline cores were designed at a medium frequency range. The first MFT, MFT1, was designed at $75 \%$ of its maximum flux density $(0.9 \mathrm{~T})$. The tests on MFT1 show that the core losses were far lower than the winding losses. Encouraged by this last result and the favorable thermic properties of nanocrystalline materials, we designed the second MFT, MFT2, at a maximum flux density, $B_{\max }=1.2 \mathrm{~T}$. The results were: 1 ) a $25 \%$ reduction in the transformer winding, 2) a higher power density, and 3) a lower MTF building cost. These values were achieved while maintaining a high efficiency $(>98 \%)$. Thus, an accurate transformer performance is evidenced in the math analysis, the computer simulations, and the experimental results when using 
a prototype working at $1 \mathrm{kVA}$ and $250 \mathrm{~V}$ at $5 \mathrm{kHz}$. All these results confirm the effectiveness of the design procedure presented in this work.

This paper is organized as follows. Section 2 introduces the medium-frequency transformer design procedure and transformer designs at $75 \%$ and $100 \%$ of $B_{\max }$. Section 3 presents the calculation of the two MFTs, the simulations, and the two MFT prototypes. Section 4 shows the discussion. Finally, in Section 5, conclusions are presented.

\section{Medium-Frequency Transformer Design Procedure}

\subsection{Transformer Design}

The MTF design technique of this work was developed by taking the algorithm proposed in [22] as a reference. The critical difference of the proposed technique [2], regarding [22] and other design techniques, including the standard procedure, was the modification about how the losses of the nanocrystalline cores were computed in the product of areas method [22]. In this way, the resulting MTF design that was obtained with the proposed technique exhibiting a higher efficiency at a medium frequency of $5 \mathrm{kHz}$.

The product of areas method was based on finding a power capacity that could be held by a core, as stated in Equation (1) [22].

$$
A_{p}=W_{a} A_{c}=\frac{P_{t}\left(10^{4}\right)}{B_{a c} f J K_{f} K_{u}}
$$

where $A_{p}$ is the product of areas, $W_{a}$ and $A_{c}$ are the window area and core cross-sectional area, respectively, $P_{t}$ is the apparent power, $B_{a c}$ is the magnetic flux density, $f$ is the frequency, $J$ is the current density, $K_{f}$ is the waveform coefficient, and $K_{u}$ is the winding fill factor.

The detailed math calculations on nanocrystalline core selection, winding turns, core losses, winding losses, and the methodology validation for medium-frequency MTFs were thoroughly detailed in [2].

\subsection{Transformer Design at $75 \%$ and $100 \%$ of $B_{\max }$}

A nanocrystalline core transformer was next designed for $75 \%$ of $B_{\max }$, i.e., $B_{a c}=0.75, B_{\max }=0.9 \mathrm{~T}$, $1 \mathrm{kV}, 5 \mathrm{kHz}$, and $10 \mathrm{kVA}$. The design obtained parameters are shown in Table 1.

Table 1. Transformer design at $10 \mathrm{kVA}$ and $0.9 \mathrm{~T}$.

\begin{tabular}{cc}
\hline \multicolumn{2}{c}{ Design Data } \\
\hline$U_{\text {in }}$ & $1000 \mathrm{~V}$ \\
$U_{\text {out }}$ & $1000 \mathrm{~V}$ \\
$f$ & $5000 \mathrm{~Hz}$ \\
$I_{\text {out }}$ & $10 \mathrm{~A}$ \\
$B_{a c}$ & $0.9 \mathrm{~T}$ \\
$N_{p}$ & 278 \\
$N_{s}$ & 282 \\
$P_{c u}$ & $87 \mathrm{~W}$ \\
$P_{f e}$ & $1.51 \mathrm{~W}$ \\
$P_{t o t}$ & $88.51 \mathrm{~W}$ \\
Efficiency & $99.1 \%$ \\
$W_{a}$ & $50.26 \mathrm{~cm}^{2}$ \\
$A_{c}$ & $2 \mathrm{~cm}^{2}$ \\
$A_{p}$ & $100.53 \mathrm{~cm}^{2}$ \\
\hline
\end{tabular}

The results from calculations were validated with Matlab-Simulink by using an equivalent circuit of the MTF. Note that for such circuit, the computation of the magnetization and dispersion branch variables was required. For the dispersion branch, resistances $R_{1}$ (primary winding resistance) and 
$R_{2}$ (secondary winding resistance) were given by the product of areas method [22]. The dispersion inductance $\left(L_{d}\right)$ was computed by using Equation (2), which gives accurate results at medium frequencies $(5 \mathrm{kHz})[23]$.

Where the variables in Table 1 are input voltage $\left(U_{\text {in }}\right)$, output voltage $\left(U_{\text {out }}\right)$, frequency $(f)$, output current $\left(I_{\text {out }}\right)$, flux density $\left(B_{a c}\right)$, the number of primary winding turns $\left(N_{p}\right)$, the number of secondary winding turns $\left(N_{s}\right)$, copper conducting losses $\left(P_{c u}\right)$, core losses $\left(P_{f e}\right)$, total losses $\left(P_{t o t}\right)$, window area $\left(W_{a}\right)$, effective cross-section of the core $\left(A_{c}\right)$, and the area product $\left(A_{p}\right)$.

$$
\begin{aligned}
L_{d} & =\mu_{0} \frac{N_{L 1}^{2}}{h_{\omega}} m_{1}\left[M L T_{i s o} m_{1} d_{i s o}+M L T_{p r i} \frac{\left(m_{1}-1\right)\left(2 m_{1}-1\right)}{6} d_{i n s 1}\right. \\
& +M L T_{\text {sec }} \frac{m_{1}\left(m_{2}-1\right)\left(2 m_{2}-1\right)}{6 m_{2}} d_{i n s 2} \\
& +M L T_{p r i} \frac{\sin \left(\frac{2 \Delta_{1}}{\alpha \delta}\right) 4 \alpha \delta^{2}\left(m_{1}^{2}-1\right)+4 d_{p r i}\left(2 m_{1}^{2}+1\right)}{24\left(\sin \frac{2 \Delta_{1}}{\alpha \delta}\right)^{2}} \\
& -M L T_{p r i} \frac{\alpha \delta^{2}\left(\frac{4 \Delta_{1}}{\alpha \delta}\right)\left(2 m_{1}^{2}+1\right)-8 d_{p r i}\left(1-m_{1}^{2}\right) \cos \left(\frac{2 \Delta_{1}}{\alpha \delta}\right)}{24\left(\sin \frac{2 \Delta_{1}}{\alpha \delta}\right)^{2}} \\
& +M L T_{\sec } \frac{m_{1}}{m_{2}} \frac{\sin \left(\frac{2 \Delta_{2}}{\alpha \delta}\right) 4 \alpha \delta^{2}\left(m_{2}^{2}-1\right)+4 d_{s e c}\left(2 m_{2}^{2}+1\right)}{24\left(\sin \frac{2 \Delta_{2}}{\alpha \delta}\right)^{2}} \\
& -M L T_{\sec } \frac{m_{1}}{m_{2}} \frac{\alpha \delta^{2} \sin \left(\frac{4 \Delta_{2}}{\alpha \delta}\right)\left(2 m_{2}^{2}+1\right)}{24\left(\sin \frac{2 \Delta_{2}}{\alpha \delta}\right)^{2}} \\
& \left.+M L T_{\sec } \frac{m_{1}}{m_{2}} \frac{8 d_{\sec }\left(1-m_{2}^{2}\right) \cos \left(\frac{2 \Delta_{2}}{\alpha \delta}\right)}{24\left(\sin \frac{2 \Delta_{2}}{\alpha \delta}\right)^{2}}\right]
\end{aligned}
$$

where:

$\mu_{0}=$ vacuum permeability

$d_{\text {iso }}=$ isolation distance

$d_{\text {ins } 1}=$ insulation distance between the layers of the

$N_{L 1}=$ turns per layer

primary

$d_{\text {ins } 2}=$ insulation distance between the layers of the

$h_{\omega}=$ winding height

secondary

$m_{1}=$ number of layers in the primary

$m_{2}=$ number of layers in the secondary

$d_{p r i}=$ thickness of the primary

$d_{s e c}=$ thickness of the secondary

$M L T_{\text {iso }}=$ mean length of the isolation distance

$M L T_{\text {pri }}=$ mean length turns of primary portion

$M L T_{\text {sec }}=$ mean length turns of secondary portion

$\Delta_{1}=$ penetration ratio of the primary, $\Delta_{1}=\frac{d_{p r i}}{\delta}$

$\Delta_{2}=$ penetration ratio of the primary, $\Delta_{2}=\frac{d_{s e c}}{\delta}$

$\alpha=\frac{1+j}{\delta}$ where $\delta$ is the skin depth

The magnetization inductance $\left(L_{m}\right)$ is calculated with Equation (3). This equation was proposed in [21] and validated in [24] for the medium frequency range $(5 \mathrm{kHz})$.

$$
L_{m}=\frac{\mu_{r} \mu_{0} N^{2} A_{c}}{l_{c}}
$$

where $N$ is the number of turns and $l_{c}$ is the mean length of the closed magnetic path around the core. Equations (2) and (3) are part of the mathematical model of the MTF equivalent circuit implemented in Matlab-Simulink (see Table 2). The cases of study were simulated by using a voltage source of $1 \mathrm{kV} / 5$ $\mathrm{kHz} / 10 \mathrm{~A}$. 
Table 2. Required equivalent circuit model data for the simulation of the $10 \mathrm{kVA} / 0.9 \mathrm{~T}$ medium frequency transformer (MTF).

\begin{tabular}{lc}
\hline & Required Data \\
\hline$U_{\text {in }}$ & $1000 \mathrm{~V}$ \\
$U_{\text {out }}$ & $1000 \mathrm{~V}$ \\
\hline \multicolumn{2}{c}{ Winding 1 parameters } \\
\hline$I_{\text {out }}$ & $10 \mathrm{~A}$ \\
$B_{a c}$ & $0.9 \mathrm{~T}$ \\
$N_{p}$ & 278 \\
\hline \multicolumn{2}{c}{ Winding 2 parameters } \\
\hline$P_{c u}$ & $87 \mathrm{~W}$ \\
$P_{f e}$ & $1.51 \mathrm{~W}$ \\
$P_{\text {tot }}$ & $88.51 \mathrm{~W}$ \\
\hline Magnetization resistance and inductance \\
\hline$W_{a}$ & $50.26 \mathrm{~cm}^{2}$ \\
$A_{c}$ & $2 \mathrm{~cm}^{2}$ \\
\hline
\end{tabular}

The resulting waveforms of the input and output voltages and currents are shown in Figure 1. Though the main application of MTFs is as part of DC-DC converters, in which square waveforms are used, in this work, for convenience, the sine wave was used instead as the stimulus for purposes of simulating and experimenting with the MFT prototype. Taking into consideration that core losses are higher for sine waves than for square waves [25], a reduction in core losses is expected once the MFT operates with a $5 \mathrm{kHz}$ square wave excitation. Table 3 shows the input voltage, output voltage, and current $\left(U_{i n}, U_{\text {out }}, I_{\text {in }}, I_{\text {out }}\right)$ values that were obtained from simulations. The final efficiency was $98.9 \%$.
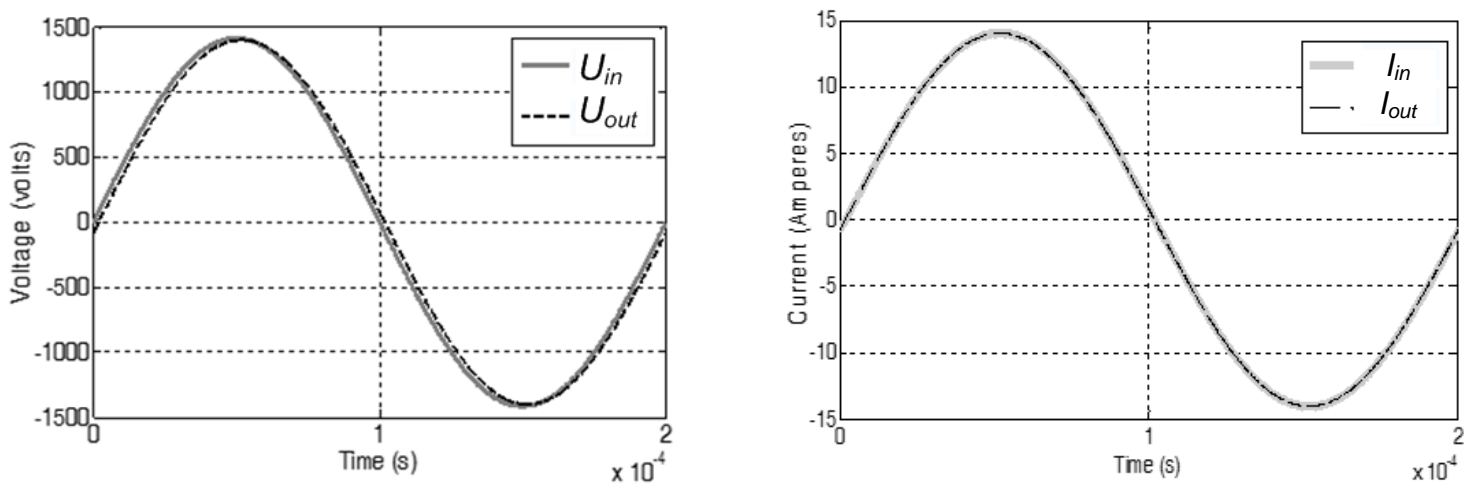

Figure 1. Input and output voltages and currents of the $10 \mathrm{kVA} / 0.9 \mathrm{~T}$ MFT.

Table 3. Voltages and currents of the primary and secondary winding of the $10 \mathrm{kVA} / 0.9 \mathrm{~T} \mathrm{MTF}$.

\begin{tabular}{cc}
\hline \multicolumn{2}{c}{ Voltages and Currents } \\
\hline$U_{\text {in }}(R M S)$ & $1000 \mathrm{~V}$ \\
$U_{\text {out }}(R M S)$ & $990.1 \mathrm{~V}$ \\
$I_{\text {in }}(R M S)$ & $9.913 \mathrm{~A}$ \\
$I_{\text {out }}(R M S)$ & $9.901 \mathrm{~A}$ \\
Efficiency & $98.90 \%$ \\
\hline
\end{tabular}

According to the classical transformer design theory, the optimal density flux $\left(B_{0}\right)$ is achieved when the core losses $\left(P_{f e}\right)$ are equal to the copper conduction losses $\left(P_{c u}\right)$ [21], as shown in Figure 2. Observe that at $B_{0}$, the total MTF losses $\left(P_{t o t}\right)$ were at their minimum. 


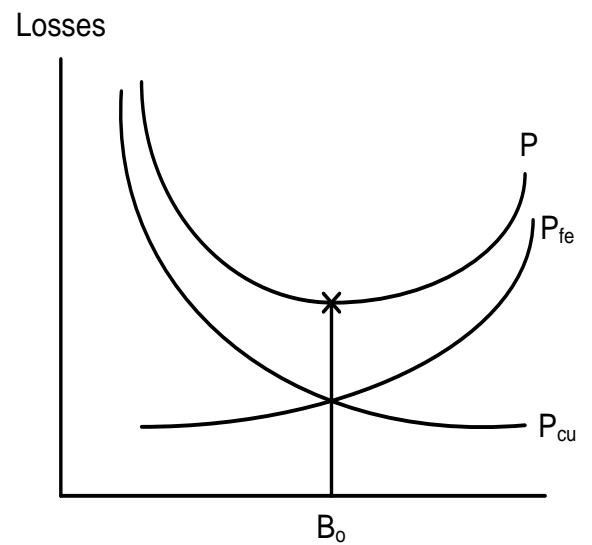

Figure 2. Flux density optimal design point $B_{0}$.

For the nanocrystalline MTF core, $P_{f e}$ was lower than $P_{c u}$ at $B_{a c}=0.9 \mathrm{~T}$, as is shown in Table 1 . Therefore, it was feasible to increase $B_{a c}$ to $B_{\max }$, i.e., up to $1.2 \mathrm{~T}$ for the nanocrystalline cores (Vitroperm500F). On these grounds, the resulting design parameters of a $10 \mathrm{kVA} / 1.2 \mathrm{~T}$ MFT are shown in Table 4.

Table 4. Transformer design data for a $10 \mathrm{kVA} / 1.2 \mathrm{~T}$ MFT.

\begin{tabular}{cc}
\hline \multicolumn{2}{c}{ Design Data } \\
\hline$U_{i n}$ & $1000 \mathrm{~V}$ \\
$U_{\text {out }}$ & $1000 \mathrm{~V}$ \\
$f$ & $5000 \mathrm{~Hz}$ \\
$I_{\text {out }}$ & $10 \mathrm{~A}$ \\
$B_{a c}$ & $1.2 \mathrm{~T}$ \\
$N_{p}$ & 209 \\
$N_{s}$ & 212 \\
$P_{c u}$ & $65.4 \mathrm{~W}$ \\
$P_{f e}$ & $2.12 \mathrm{~W}$ \\
$P_{\text {tot }}$ & $67.52 \mathrm{~W}$ \\
Efficiency & $99.3 \%$ \\
$W_{a}$ & $50.26 \mathrm{~cm}^{2}$ \\
$A_{c}$ & $2 \mathrm{~cm}^{2}$ \\
$A_{p}$ & $100.53 \mathrm{~cm}^{2}$ \\
\hline
\end{tabular}

By comparing the MTF design at $0.9 \mathrm{~T}$ with the one at $1.2 \mathrm{~T}$, it can be noticed that $P_{c u}$ was reduced from 88.51 to $65.4 \mathrm{~W}(26.1 \%)$ while $P_{f e}$ and the efficiency increased from 1.51 to $2.12 \mathrm{~W}(40.3 \%)$ and $99.1 \%$ to $99.3 \%$, respectively.

By designing at $B_{\max }$, a critical reduction in the winding turns was also achieved. For instance, the 278 turns that were needed for $B_{a c}=0.9 \mathrm{~T}$ (see Table 4) were reduced to only 209 turns for $B_{a c}=1.2 \mathrm{~T}$, as presented in Table 2. This represented a turn reduction of $24.8 \%$. The number of winding turns was calculated with Equation (4). It can be noticed that as $B_{a c}$ increased, then the number of turns decreased.

$$
N_{p}=\frac{V_{\text {in }} 10^{4}}{k_{f} B_{a c} f A_{c}}
$$

Despite the core losses increment at $B_{\max }$, these losses were still lower than the winding losses. However, these losses were not good enough for new MTFs that were designed by using the conventional transformer design theory [21], mainly because this theory states that the optimal design is when core losses are equal to the copper conducting losses.

When increasing $B_{a c}$ to $B_{\max }$ in nanocrystalline core MTFs, the number of winding turns decreases. Consequently, the manufacturing cost is lowered while obtaining a higher power density. This can be 
achieved without disregarding the main design MTF constrictions discussed in Section 3, such as the tolerance margin of core saturation that is allowable after exceeding the nominal MTF voltage.

These results showed the favorable magnetic properties of nanocrystalline materials, which represent a significant improvement over other core materials for MFTs. The improvement in core materials has significantly reduced power losses. On the other hand, winding technology has remained relatively much the same.

\section{MTF Laboratory Prototypes}

As part of the validation of the MFT design procedure focused on $B_{\max }$, we built two MFT lab prototypes: 1) $1 \mathrm{kVA}, 5 \mathrm{kHz}, 250 \mathrm{~V}$ and $0.9 \mathrm{~T}$, which was named MFT1; and 2) $1 \mathrm{kVA}, 5 \mathrm{kHz}, 250 \mathrm{~V}$ and $1.2 \mathrm{~T}$, which was named MFT2. The parameter values that were obtained from the design procedure for each MFT are shown in Table 5.

Table 5. Transformer design data for MFT1 and MFT2.

\begin{tabular}{ccc}
\hline \multicolumn{3}{c}{ Design Data } \\
\hline Parameter & MFT1 & MFT2 \\
\hline$U_{\text {in }}$ & $250 \mathrm{~V}$ & $250 \mathrm{~V}$ \\
$U_{\text {out }}$ & $250 \mathrm{~V}$ & $250 \mathrm{~V}$ \\
$F$ & $5000 \mathrm{~Hz}$ & $5000 \mathrm{~Hz}$ \\
$I_{\text {out }}$ & $4 \mathrm{~A}$ & $4 \mathrm{~A}$ \\
$B_{a c}$ & $0.9 \mathrm{~T}$ & $1.2 \mathrm{~T}$ \\
$N_{p}$ & 147 & 110 \\
$N_{s}$ & 150 & 112 \\
$P_{c u}$ & $11.74 \mathrm{~W}$ & $8.78 \mathrm{~W}$ \\
$P_{f e}$ & $0.62 \mathrm{~W}$ & $1.12 \mathrm{~W}$ \\
$P_{\text {tot }}$ & $12.36 \mathrm{~W}$ & $9.89 \mathrm{~W}$ \\
Efficiency & $98.80 \%$ & $99.01 \%$ \\
$W_{a}$ & $19.63 \mathrm{~cm}^{2}$ & $19.63 \mathrm{~cm}^{2}$ \\
$A_{c}$ & $0.95 \mathrm{~cm}^{2}$ & $0.95 \mathrm{~cm}^{2}$ \\
$A_{p}$ & $18.65 \mathrm{~cm}^{4}$ & $18.65 \mathrm{~cm}^{4}$ \\
\hline
\end{tabular}

\subsection{Transformer Calculation}

If $B_{a c}$ increases, then $N_{p}$ decreases, as expressed by Equation (4). Therefore, using $B_{\max }=1.2$ $\mathrm{T}$ (nanocrystalline materials) led to a $25.17 \%$ reduction in the number of winding turns from 147 at $B_{a c}=0.9 \mathrm{~T}$ to 110 at $B_{a c}=B_{\max }=1.2 \mathrm{~T}$ (see Table 5).

A side effect of using $B_{a c}=B_{\max }$ is the increase of $P_{f e}$. However, this increment does not adversely affect the MTF efficiency that is achieved with nanocrystalline materials. For the designed MFTs, $P_{f e}$ increased from $0.62 \mathrm{~W}$ (MTF1) to $1.12 \mathrm{~W}$ (MFT2).

\subsection{Simulation}

The dispersion and magnetization inductances are parameters that were needed in the simulations of the MTF behavior under different operation conditions. These parameters were calculated by using Equations (2) and (3). MFT1 and MFT2 were both simulated in Matlab-Simulink.

Table 6 shows the simulating data of the equivalent circuit of MFT1 and MFT2. A power source of $250 \mathrm{~V}$ at $5 \mathrm{kHz}$ and a $62.5 \Omega$ load were used in this case. 
Table 6. Simulation data for the MFTs.

\begin{tabular}{|c|c|c|}
\hline Required Data & MFT1 & MFT2 \\
\hline$P_{\text {out }}(V A)$ & 1000 & 1000 \\
\hline$f(H z)$ & 5000 & 5000 \\
\hline \multicolumn{3}{|c|}{ Winding 1 parameters } \\
\hline$U_{\text {in }}(\mathrm{RMS})$ & 250 & 250 \\
\hline$R_{1}(\Omega)$ & 0.2729 & 0.2042 \\
\hline$L_{\mathrm{d} 1}(\mathrm{H})$ & 0.000031 & 0.0000238 \\
\hline \multicolumn{3}{|c|}{ Winding 2 parameters } \\
\hline$U_{\text {out }}(\mathrm{RMS})$ & 250 & 250 \\
\hline$R_{2}(\Omega)$ & 0.2729 & 0.2042 \\
\hline$L_{\mathrm{d} 2}(\mathrm{H})$ & 0.000031 & 0.0000238 \\
\hline \multicolumn{3}{|c|}{ Magnetization resistance and inductance } \\
\hline$R_{\mathrm{m}}(\Omega)$ & 111270 & 111270 \\
\hline$L_{\mathrm{m}}(\mathrm{H})$ & 0.194 & 0.1087 \\
\hline
\end{tabular}

The input/output voltage and current waveforms of MFT1 resulting from simulations are shown in Figure 3. The RMS values of these waveforms are summarized in Table 7 . The efficiency that was calculated for MTF1 was $98.8 \%$, strictly lower than the $99 \%$ that resulted from the simulations. These results encouraged the building of the lab prototypes.

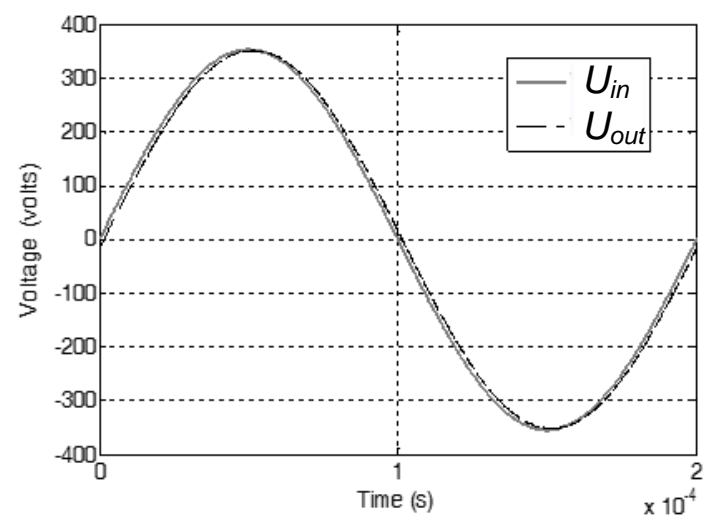

(a)

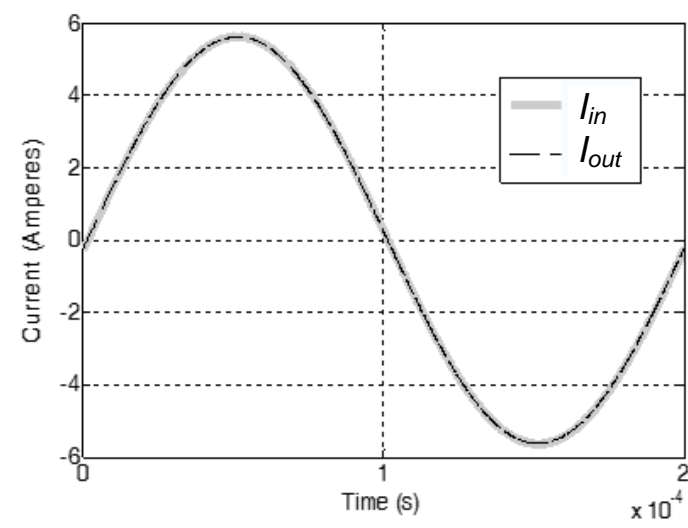

(b)

Figure 3. Input and output voltages and currents of MFT1 at $1 \mathrm{kVA}$.

Table 7. RMS values of voltages and currents from simulations of the MFTs.

\begin{tabular}{ccc}
\hline Voltages and Currents & MFT1 & MFT2 \\
\hline$U_{\text {in }}(R M S)$ & $250 \mathrm{~V}$ & $250 \mathrm{~V}$ \\
$U_{\text {out }}(R M S)$ & $247.7 \mathrm{~V}$ & $248.25 \mathrm{~V}$ \\
$I_{\text {in }}(R M S)$ & $3.966 \mathrm{~A}$ & $3.98 \mathrm{~A}$ \\
$I_{\text {out }}(R M S)$ & $3.963 \mathrm{~A}$ & $3.97 \mathrm{~A}$ \\
Efficiency & $99 \%$ & $99.05 \%$ \\
\hline
\end{tabular}

Figure 4 shows the input/output voltage and current waveforms that resulted from simulating the MTF2. The RMS values of these waveforms are summarized in Table 7 . The difference between the efficiency that was obtained from simulations and that which was obtained from calculations was minimal, as they were $99.05 \%$ and $99.01 \%$, respectively. These results were also validated with experimentation. 


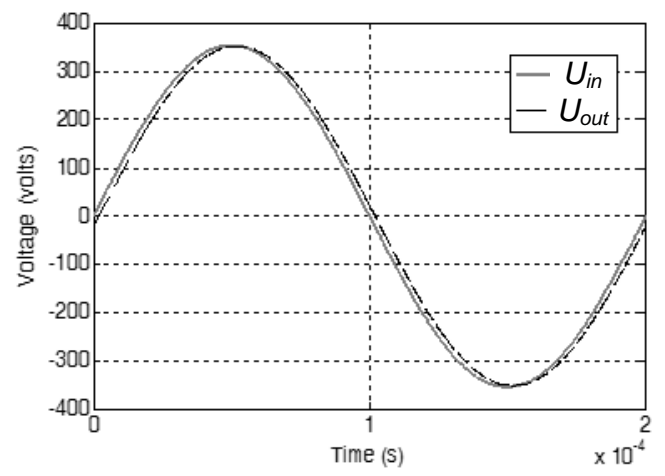

(a)

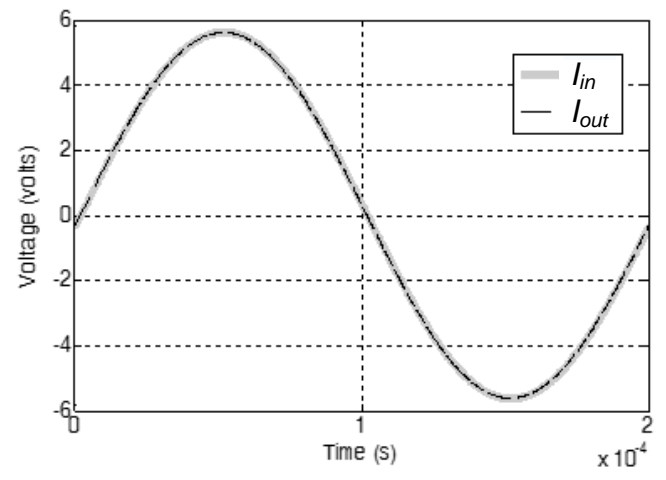

(b)

Figure 4. Input and output voltages and currents of MFT2 at 1 kVA.

\subsection{MFT Prototypes}

The two MTF laboratory prototypes were developed based on the data reported in Table 5 . The prototype, MFT1, was designed with $B_{a c}=0.9 \mathrm{~T}$ (Figure 5a), and the second, MFT2, was designed with $B_{a c}=1.2 \mathrm{~T}$ (Figure 5b).

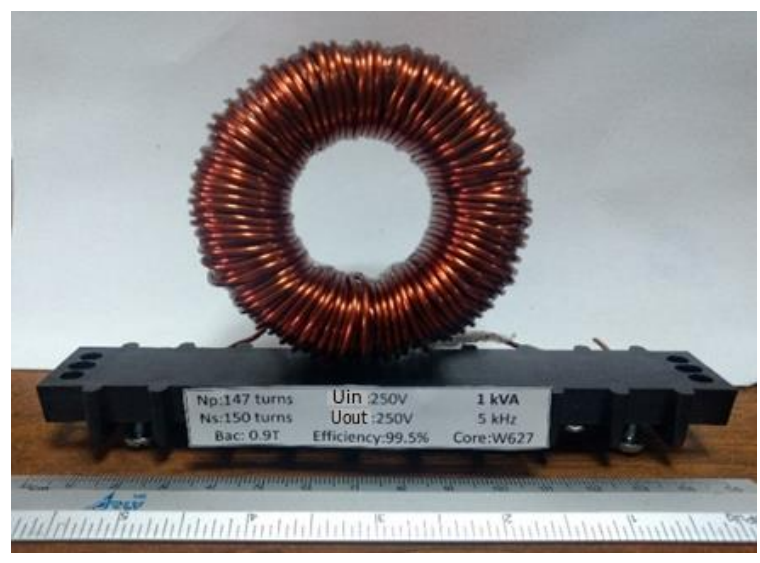

(a)

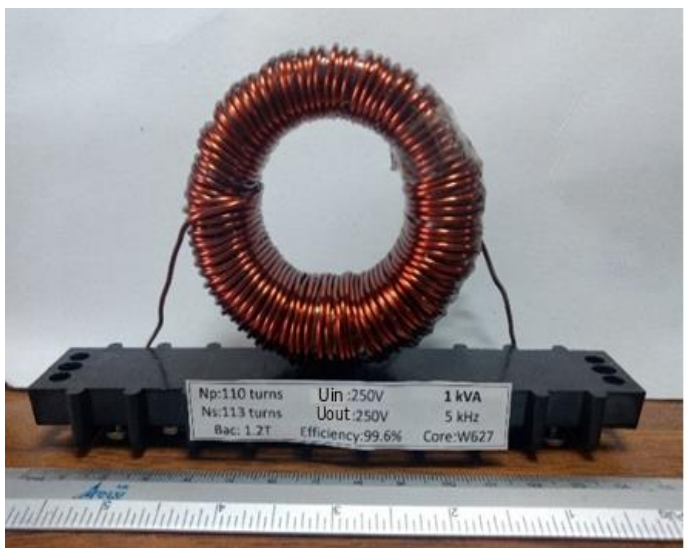

(b)

Figure 5. (a) MFT1 at $0.9 \mathrm{~T}$; (b) MFT2 at $1.2 \mathrm{~T}$.

Figure 6 shows MTF1 and the testbed. The prototype was fed with an AC POWER SOURCE/ANALYZER AGILENT 6834b. At experimentation, the input voltage was set to $250 \mathrm{~V}$, and $5 \mathrm{kHz}$, to test the MTF1 prototype with a load of $60 \Omega$.

The efficiency of MFT1 that was measured at the laboratory was $98.62 \%$. This value deviated less than $1 \%$ of the theoretical efficiency of $98.8 \%$ and the efficiency of $99 \%$ from simulations. These results confirmed the effectiveness of the MTF designs presented in [2].

Figure 7 shows the MTF2 prototype in the laboratory. The testbed was the same as the one that was used to test MFT1. In this case, the efficiency that was measured in the laboratory was $99.01 \%$ while the efficiencies that was obtained from the calculation and simulations were $99.01 \%$ and $99.05 \%$, respectively. Table 8 shows the output power, input power, winding losses, core losses, and total losses of the MFT1 and MFT2 lab prototypes. Due to the increase of the flux density, the core losses of MFT2 increased, and these were higher compared to those of MFT1. However, the losses in the winding decreased in MFT2 because the winding was reduced. Additionally, there was a $25 \%$ reduction in winding turns. All together this implies a higher power density and a lower building cost. These results show the excellence performance of the MTF that was operating at $B_{\max }$. 


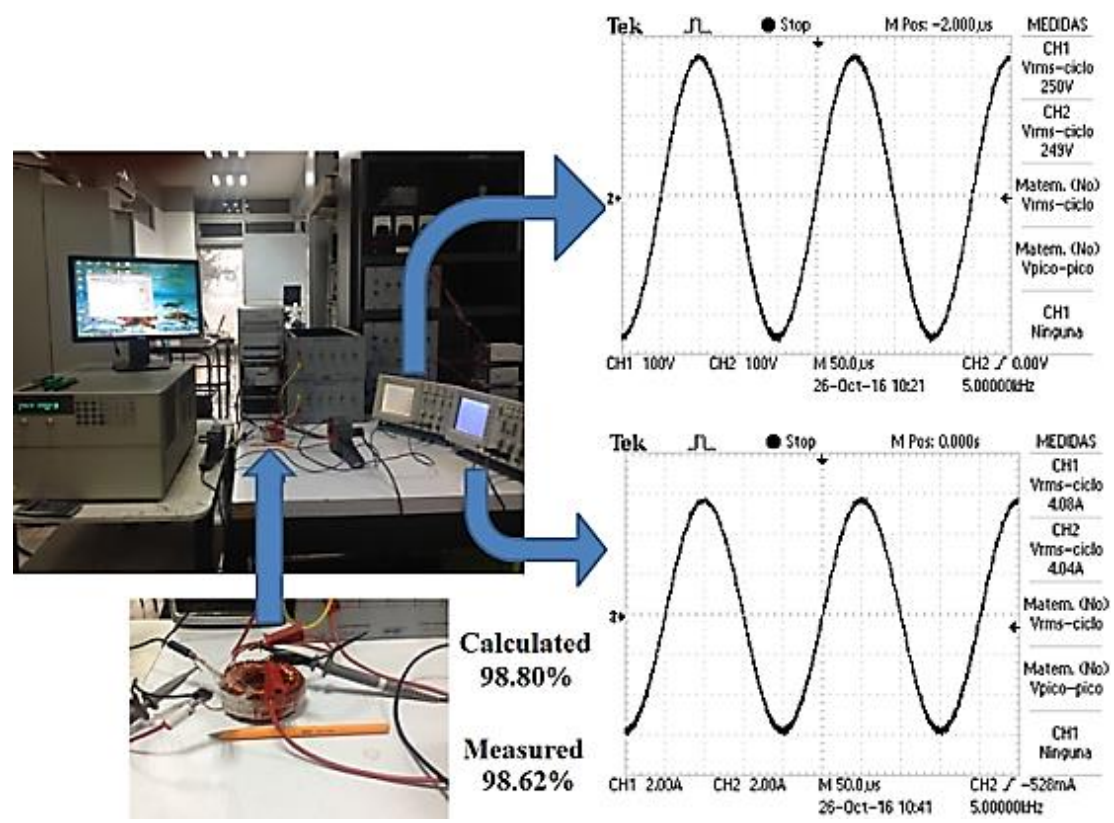

Figure 6. MFT1 lab prototype that was tested by using $1 \mathrm{kVA}$ at $5 \mathrm{kHz}$.

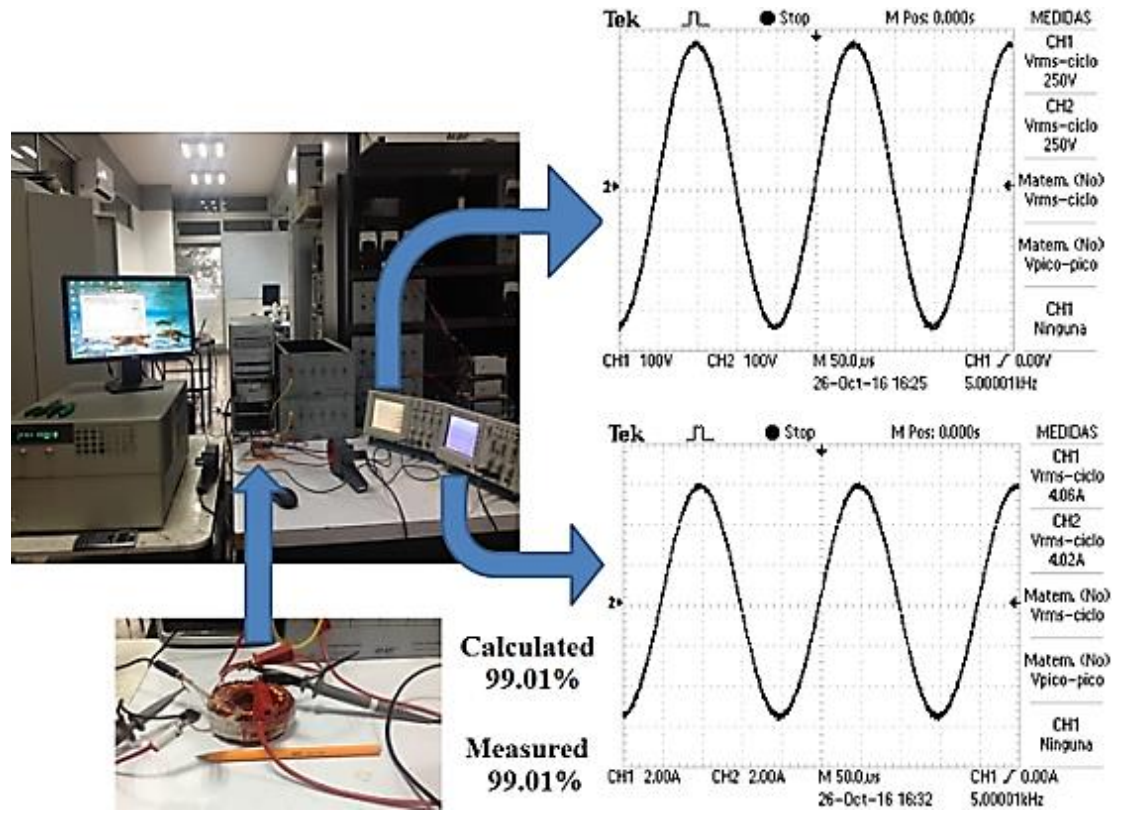

Figure 7. MFT2 lab prototype that was tested by using $1 \mathrm{kVA}$ at $5 \mathrm{kHz}$.

Table 8. Losses and power of input and output of the MFT1 and MFT2 lab prototypes.

\begin{tabular}{ccc}
\hline Measurement & MFT1 & MFT2 \\
\hline Input power & $1002 \mathrm{~W}$ & $1015 \mathrm{~W}$ \\
Output power & $1005.96 \mathrm{~W}$ & $1005 \mathrm{~W}$ \\
Core losses & $1.15 \mathrm{~W}$ & $2.02 \mathrm{~W}$ \\
Winding losses & $12.84 \mathrm{~W}$ & $7.97 \mathrm{~W}$ \\
Total losses & $14.04 \mathrm{~W}$ & $10 \mathrm{~W}$ \\
\hline
\end{tabular}

The voltage of the secondary winding of MFT2 also increased and was higher compared to such a voltage of MFT1. The waveforms are shown in Figure 3; Figure 4 for the simulation cases and Figure 6; 
Figure 7 for the prototype cases. This effect in the voltage was because of a decrement in the number of turns in the winding. Such a decrement also led to a reduction of the dispersion inductance, and from this, a lower dispersed flow was obtained and the voltage of the secondary winding increased.

Figure 8 shows the behavior of the efficiency for both transformers at different frequencies. From 3.1 to $4.3 \mathrm{kHz}$, the efficiency of MFT1 was greater than $98 \%$ at nominal power and higher than the efficiency of MFT2. From 4.4 to $5 \mathrm{kHz}$, the efficiency of MFT2 was slightly higher. This was due to the increase in the flux density in the design of MFT2. This condition decreased the frequency range in which MFT2 began to behave efficiently.

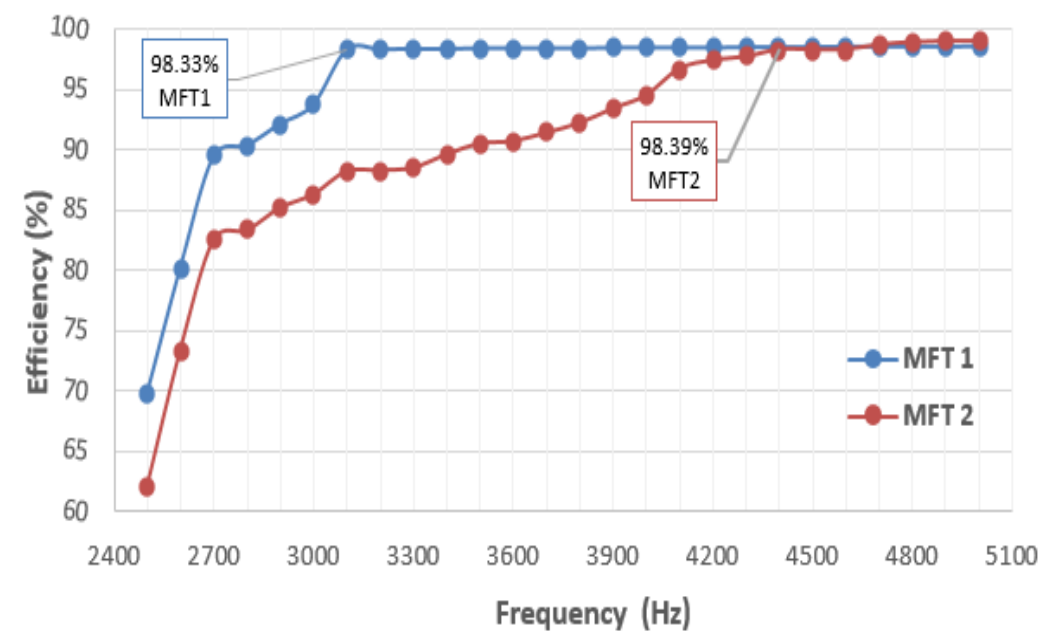

Figure 8. Efficiency vs. frequency for both MFTs.

Figure 9 shows the behavior of both MFTs with different load values, from $25 \%$ to $150 \%$ of the nominal load $(100 \%=60 \Omega=$ nominal load). For $125 \%$ of the nominal load in MFT2, the output voltage was $279 \mathrm{~V}$ with a current $=4 \mathrm{~A}$. This voltage level was within the tolerance margin that was allowed above the nominal voltage $(12 \%, 280 \mathrm{~V}$ limit). Additionally, the obtained efficiency was higher than $98 \%$. For $150 \%$ of the nominal load, the output voltage and current were $288 \mathrm{~V}$ and $3.95 \mathrm{~A}$, respectively. This voltage level exceeded $12 \%$ of the nominal voltage level, and the efficiency was reduced to $86.63 \%$.

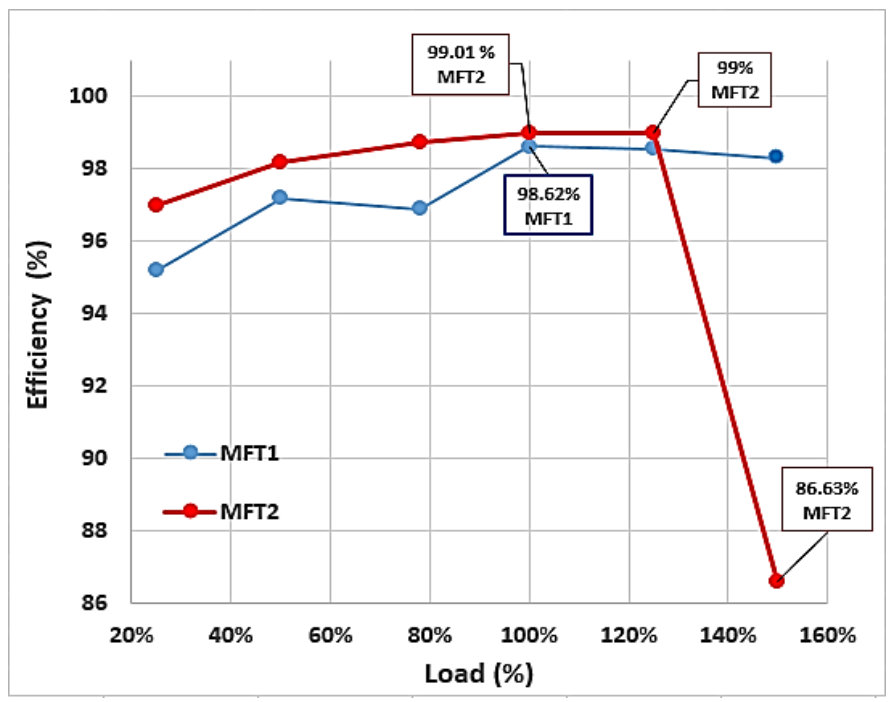

Figure 9. Efficiency of both MFTs at different loads. 
Figure 10 shows the thermic images of the MTF prototype that was taken with a Milwaukee M12TM $7.8 \mathrm{kP}$ thermal camera after 30 minutes of operation at nominal voltages and currents. Observe that there was a temperature reduction from 75.6 to $75.2^{\circ} \mathrm{C}$ between MTF1 and MFT2 operation at the hottest winding point. For dry transformers, the temperature raise was $110 / 135^{\circ} \mathrm{C}$ at the hottest winding point, and the tolerance of the nanocrystalline cores (VITROPERM 500F) was $105^{\circ} \mathrm{C}$.

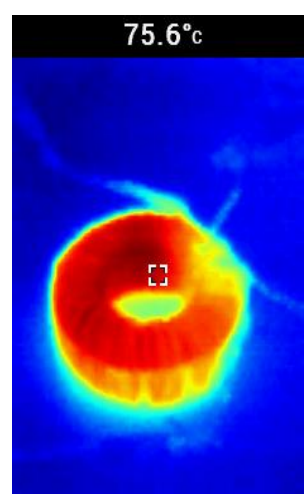

(a)

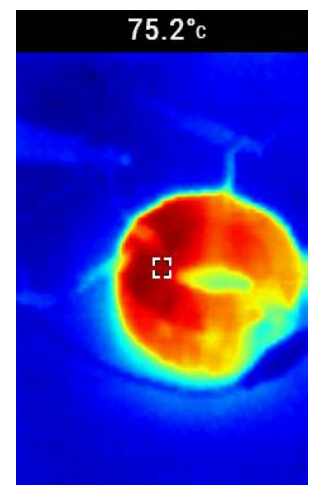

(b)

Figure 10. MFT temperature: (a) MFT1; (b) MFT2.

Figure 11 shows the voltage tolerance above the nominal voltage $(250 \mathrm{~V})$ that was exhibited by the MTF2 prototype. In Figure 11a, it is clear that a raise of $12 \%$ above the nominal voltage (to $280 \mathrm{~V}$ ) did not significantly affect the MTF prototype's overall behavior. Efficiency remained at $98.8 \%$.

Similarly, Figure $11 \mathrm{~b}$ shows the effects of the $13 \%$ raising in the voltage above its nominal value, i.e., from 250 to $283 \mathrm{~V}$. In this case, the MTF2 prototype showed some signs of saturation in the input voltage, output voltage, current, and efficiency down to $93.88 \%$. The third case, shown in Figure 11c, explored the effects of raising voltage to $15 \%$ above nominal. In this condition, core saturation was evident, voltage and current waveforms were distorted, and efficiency dropped by up to $86.93 \%$. Table 9 presents the previous results. Table 10 presents the THD of both MFTs at the voltages shown in Table 9.

Table 9. Tolerance above the nominal voltage of MFT2.

\begin{tabular}{cccccc}
\hline & $\boldsymbol{U}_{\text {in }}$ & $\boldsymbol{U}_{\text {out }}$ & $\boldsymbol{I}_{\text {in }}$ & $\boldsymbol{I}_{\text {out }}$ & Efficiency \\
\hline Nominal voltage $\left(U_{\text {nom }}\right)$ & $250 \mathrm{~V}$ & $250 \mathrm{~V}$ & $4.06 \mathrm{~A}$ & $4.02 \mathrm{~A}$ & $99.01 \%$ \\
$12 \%$ above $U_{\text {nom }}$ & $280 \mathrm{~V}$ & $279 \mathrm{~V}$ & $4.55 \mathrm{~A}$ & $4.48 \mathrm{~A}$ & $98.11 \%$ \\
$13 \%$ above $U_{\text {nom }}$ & $283 \mathrm{~V}$ & $282 \mathrm{~V}$ & $4.84 \mathrm{~A}$ & $4.56 \mathrm{~A}$ & $93.88 \%$ \\
$15 \%$ above $U_{\text {nom }}$ & $287 \mathrm{~V}$ & $286 \mathrm{~V}$ & $4.65 \mathrm{~A}$ & $4.65 \mathrm{~A}$ & $86.93 \%$ \\
\hline
\end{tabular}

Table 10. THD for both MFTs at the voltages shown in Table 9.

\begin{tabular}{ccccc}
\hline & \multicolumn{2}{c}{ MFT1 } & \multicolumn{2}{c}{ MFT2 } \\
\cline { 2 - 5 } & THD $_{\mathbf{I}}$ & THD $_{\mathbf{V}}$ & THD $_{\mathbf{I}}$ & THD $_{\mathbf{V}}$ \\
\hline Nominal voltage $\left(U_{\text {nom }}\right)$ & $0.55 \%$ & $0.52 \%$ & $0.54 \%$ & $0.52 \%$ \\
$12 \%$ above $\mathcal{U}_{\text {nom }}$ & $0.53 \%$ & $0.54 \%$ & $2.23 \%$ & $0.70 \%$ \\
$13 \%$ above $U_{\text {nom }}$ & $0.54 \%$ & $0.53 \%$ & $4.68 \%$ & $1.77 \%$ \\
$15 \%$ above $U_{\text {nom }}$ & $0.53 \%$ & $0.53 \%$ & $8.82 \%$ & $3.86 \%$ \\
\hline
\end{tabular}



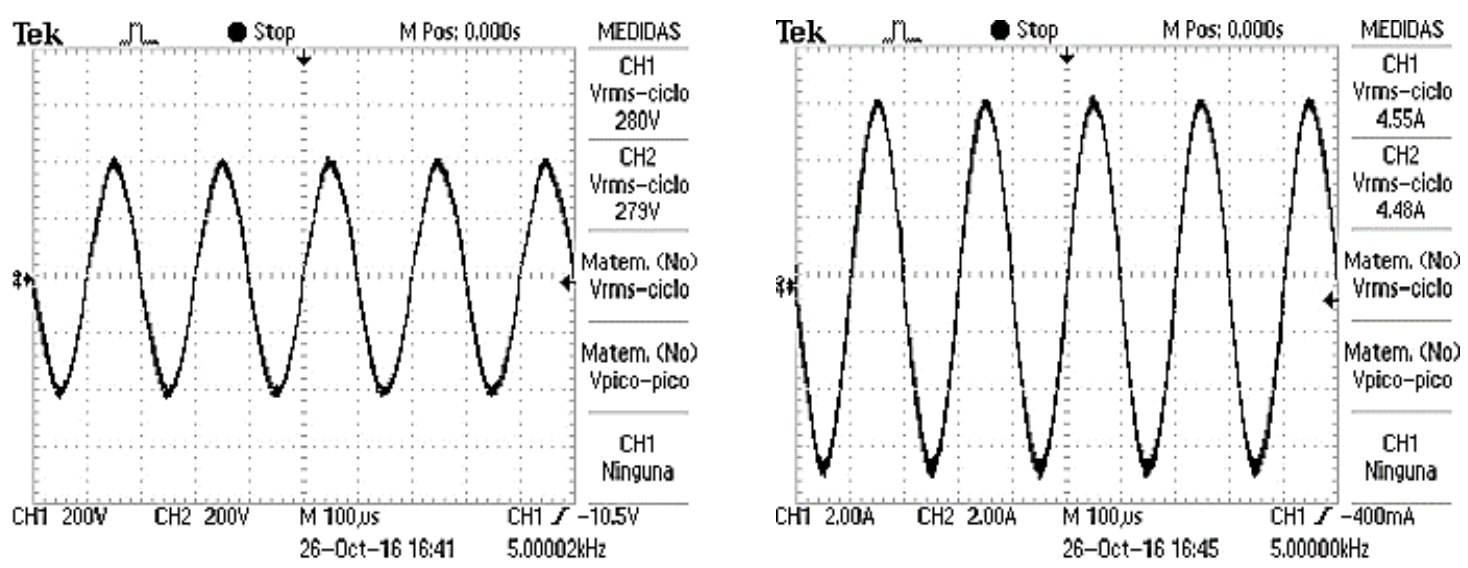

Left: $\mathrm{CH} 1=U_{\text {in }}, \mathrm{CH} 2=U_{\text {out }}$; right: $\mathrm{CH} 1=I_{\text {in }}, \mathrm{CH} 2=I_{\text {out }}$.

(a)
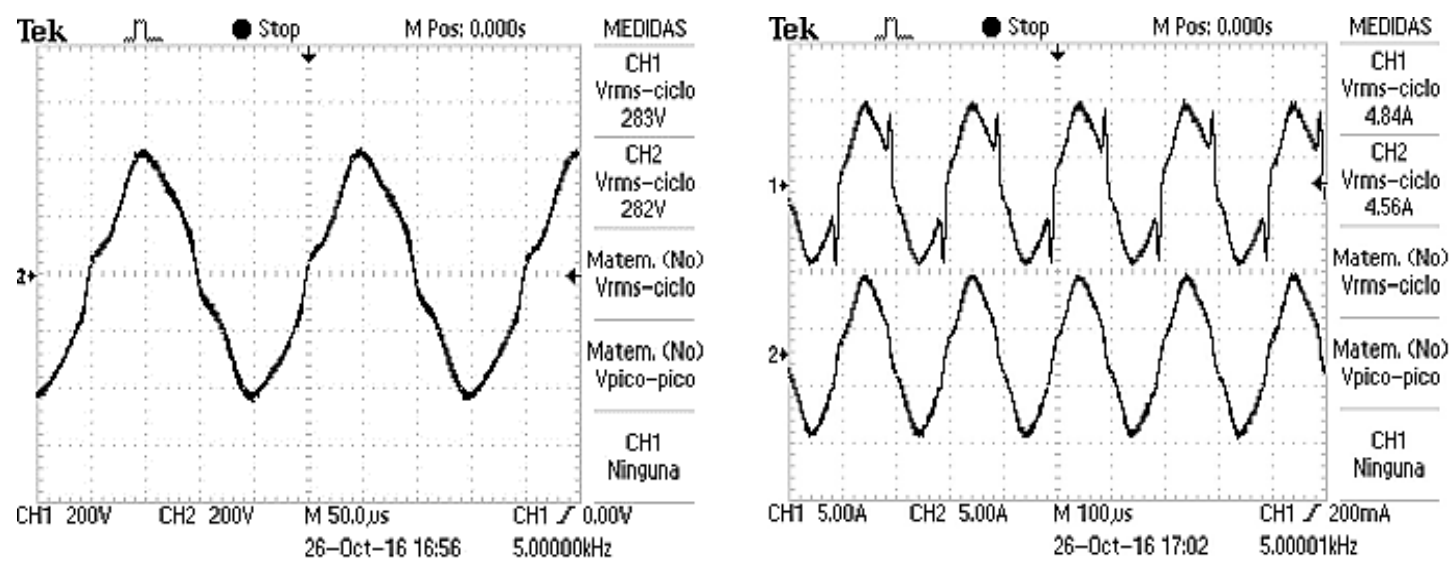

Left: $\mathrm{CH} 1=U_{\text {in }}, \mathrm{CH} 2=U_{\text {out }}$; right: $\mathrm{CH} 1=I_{\text {in }}, \mathrm{CH} 2=I_{\text {out }}$.

(b)
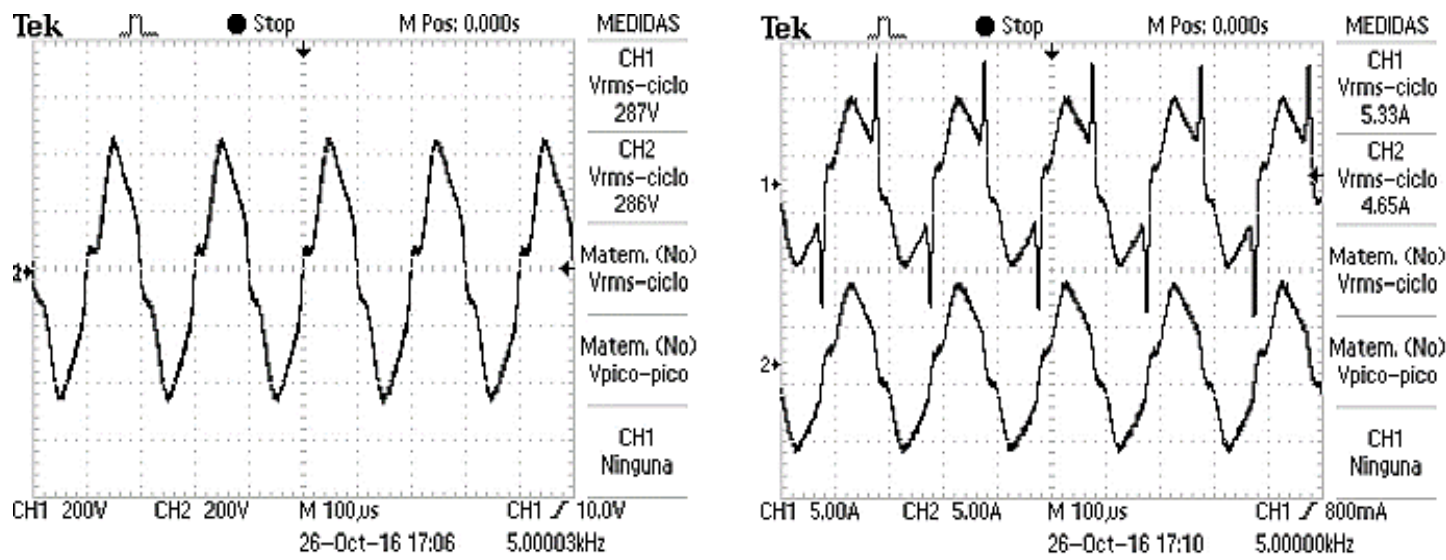

Left: $\mathrm{CH} 1=U_{\text {in }}, \mathrm{CH} 2=U_{\text {out }} ;$ right: $\mathrm{CH} 1=I_{\text {in }}, \mathrm{CH} 2=I_{\text {out }}$.

(c)

Figure 11. MFT2 maximum voltage tolerance testing: (a) 12\%, (b) 13\%, and (c) 15\%. 
After analyzing the results, it became clear that designing an MFT at maximum flux density is achievable by using nanocrystalline cores. This type of core has a safe operation zone up to $12 \%$ above the nominal voltage. Additional advantages of the proposed MFT design are a $25 \%$ cut in winding turns, a higher power density, and lower building costs.

The immediate benefits of designing an MTF at maximum flux density are reflected on improving DC-DC converters for applications on photovoltaic systems, wind power systems, electric vehicles, and solid-state transformers.

\section{Discussion}

Table 11 summarizes recent MTF design proposals [1-3,5,6] for comparison purposes. The comparison is focused on the flux density design method of each proposal. Every proposal in Table 11 includes a laboratory prototype.

Table 11. Design flux density for various MFT proposals.

\begin{tabular}{cclcc}
\hline $\begin{array}{c}\text { Design Flux } \\
\text { Density }\end{array}$ & Reference & Core & Efficiency & Power Density \\
\hline $1.2 \mathrm{~T}$ & This proposal & nanocrystalline & $>99 \%$ & $15.62 \mathrm{~kW} / 1$ \\
$0.9 \mathrm{~T}$ & Ruiz 2018, [2] & nanocrystalline & $>99 \%$ & $15.01 \mathrm{~kW} / 1$ \\
$0.9 \mathrm{~T}$ & Bahmani 2016, [5] & nanocrystalline & $>99 \%$ & $11.5 \mathrm{~kW} / 1$ \\
$0.35 \mathrm{~T}$ & Asier 2017, [1] & ferrite & $>99 \%$ & $9.25 \mathrm{~kW} / 1$ \\
$0.5 \mathrm{~T}$ & Huang 2017, [6] & silicon steel & $>99 \%$ & $2.96 \mathrm{~kW} / 1$ \\
$0.6 \mathrm{~T}$ & Harish 2017, [3] & silicon steel & $>99 \%$ & $1.29 \mathrm{~kW} / 1$ \\
\hline
\end{tabular}

From Table 11, it can be noticed that silicon steel core transformers are commonly designed for frequencies up to $1 \mathrm{kHz}$. This can be explained by the fact that higher frequencies cause higher core losses and lower transformer efficiencies [6]. The selection of the flux density level and operation frequency for silicon steel cores is done in order to achieve efficiencies higher than $98 \%$. However, if the flux density increases, the core losses also increases. As a consequence, the efficiency is reduced below $98 \%$, the minimum acceptable value.

In the case of ferrite cores, the maximum flux density is restricted between 0.4 and $0.5 \mathrm{~T}$. This restriction also limits the reachable power density. In [1], a ferrite core MTF was designed at $B_{a c}=0.35 \mathrm{~T}$, which is far below the flux density that is achievable with nanocrystalline cores.

On the other hand, nanocrystalline materials have enormous potential to develop reliable and efficient MTFs that take advantage of maximizing the design flux density to $1.2 \mathrm{~T}$ and whose benefits have been thoroughly exposed in this paper.

Regarding the power density of the works presented in Table 11 and taking into account that a higher flux density leads to a higher power density, the MFTs with the lowest power density are those designed with silicon steel at flux densities of $0.5 \mathrm{~T} \mathrm{[6]} \mathrm{and} 0.6 \mathrm{~T} \mathrm{[3],} \mathrm{and} \mathrm{the} \mathrm{lowest} \mathrm{frequency,} 1 \mathrm{kHz}$. An MFT with ferrite core [1], mostly for designs at frequencies of $20 \mathrm{kHz}$, has a higher power density than those of $[3,6]$ despite of having a lower flux density. The MFTs with the highest power density are those with nanocrystalline cores at a flux density of $0.9 \mathrm{~T}[2,5]$. Therefore, the innovative proposal of using $B_{\max }$ at $1.2 \mathrm{~T}$ is an attractive option for obtaining a higher power density than in other proposals, such as in $[2,5]$.

The novel design technique focused on $B_{\max }$, presented in this paper, is a step forward in reaching a higher power density for MFTs. This type of MFT is, in turn, an essential element for the upcoming DC-DC converter.

On the other hand, a comparison is presented in Table 12 between a conventional transformer at $50 \mathrm{~Hz} / 60 \mathrm{~Hz}$ and $1 \mathrm{kVA}$ and an MFT at $5 \mathrm{kHz}$ and $1 \mathrm{kVA}$. 
Table 12. Comparison of a conventional transformer and an MFT.

\begin{tabular}{ccccccc}
\hline Transformer & Power & Frequency & Volume & Weight & $\begin{array}{c}\text { Power } \\
\text { Density }\end{array}$ & Cost \\
\hline Conventional & $1 \mathrm{kVA}$ & $50 \mathrm{~Hz} / 60 \mathrm{~Hz}$ & $783 \mathrm{~cm}^{3}$ & $7 \mathrm{~kg}$ & $1.28 \mathrm{~kW} / 1$ & $241.18 \mathrm{USD}$ \\
MFT & $1 \mathrm{kVA}$ & $5 \mathrm{kHz}$ & $64 \mathrm{~cm}^{3}$ & $0.25 \mathrm{~kg}$ & $15.62 \mathrm{~kW} / 1$ & $67.87 \mathrm{USD}$ \\
\hline
\end{tabular}

According to Table 12, the MFT, compared to a conventional transformer, has a 12.23 times lower volume, a 28 times less weight, a 12.2 times higher power density, and a 3.55 times less cost. These results corroborate the advantages of MFTs in relation to conventional transformers.

Future research works related to this paper would be: (i) the performance of a finite element method analysis to find the maximum flux density and design frequency for various MTF core materials, (ii) the study of different DC-DC converters looking for the widening of the penetration of MTFs, (iii) the evaluation of core losses by using the finite element method and analytic MTF computations, (iv) the performance of a temperature analysis for MTFs by using ferrite, silicon steel and nanocrystalline cores, (v) the evaluation of $60 \mathrm{~Hz}$ transformers by using distinct core materials, and (vi) the elaboration of a design procedure for isolation transformers at a medium frequency.

\section{Conclusions}

The MFT is a key component in various types of DC-DC converters that are oriented to a multitude of applications of great interest at present, such as electric vehicles, renewable energy power sources, and solid-state transformers. To achieve progress in this area, an important point is to obtain the highest possible power density in the MFT. One of the main challenges to increase power density, however, is overcoming the winding and core losses in order to avoid getting inefficient MFTs $(<98 \%)$.

This work presents a design procedure for MFTs that are dedicated to increasing the power density in the MFTs with nanocrystalline cores by using their $B_{\max }(1.2 \mathrm{~T})$ as a design requirement. The validity of the design procedure was confirmed with simulations and two $1 \mathrm{kVA} / 5 \mathrm{kHz}$ laboratory prototypes that were built for this purpose. The first prototype was designed at $B_{\max }=0.9 \mathrm{~T}$ and the second at $B_{\max }=1.2 \mathrm{~T}$.

The results of this research work illustrate the advantages of designing MFTs at $B_{\max }$ with nanocrystalline cores. These advantages are a $25 \%$ reduction in the number of winding turns, a higher power density, a lower construction cost, a slightly higher efficiency $(0.4 \%)$, and a $12 \%$ tolerance over nominal voltage altogether while maintaining a high efficiency $(>98 \%)$.

The design proposal presented in this document is a step forward towards achieving higher power density in DC-DC converters that further impact applications of the highest importance for the current and next generation of distribution electrical systems.

Author Contributions: Performed prototype experiments, D.R.-R; conceptualization, D.R.-R., and E.L.M.-G.; methodology, V.V.-R., and E.L.M.-G.; validation, D.R.-R., and N.M.S.-H.; formal analysis, V.V.-R.; investigation, D.R-R., and E.L.M.-G.; writing — original draft preparation, D.R-R., and E.L.M.-G.; writing—review and editing, N.M.S.-H., and V.V.-R.; project administration, V.V.-R., and E.L.M.-G.; all authors contributed to the review of the paper. All authors have read and agreed to the published version of the manuscript.

Funding: This research received no external funding.

Acknowledgments: The authors thank the TNM (Tecnológico Nacional de México/Instituto Tecnológico de Morelia) and CONACYT for supporting our research and projects leading to the writing of present paper.

Conflicts of Interest: The authors declare no conflict of interest.

\section{References}

1. Bediaga, A.; Villar, I.; Rujas, A.; Mir, L.; Rufer, A. Multiobjective Optimization of Medium-Frequency Transformers for Isolated Soft-Switching Converters Using a Genetic Algorithm. IEEE Trans. Power Electron. 2017, 32, 2995-3006. [CrossRef] 
2. Ruiz, R.D.; Venegas, R.V.; Anaya, R.A.; Moreno, G.E.; Rodríguez, R.J. Design and prototyping medium-frequency transformers featuring a nanocrystalline core for DC-DC converter. Energy 2018, 11, 2081. [CrossRef]

3. Krishnamoorthy, H.; Daniel, M.; Ramos, J.; Enjeti, P.; Liu, L.; Aeloiza, E. Isolated AC-DC converter using medium frequency transformer for off-shore wind turbine DC collection grid. IEEE Trans. Ind. Electron. 2017, 64, 8939-8947. [CrossRef]

4. Leib, M.; Ortiz, G.; Kolar, W. Design and experimental analysis of a medium-frequency transformer for solid-state transformer applications. IEEE J. Emerg. Sel. Top. Pow. Electron. 2017, 5, 110-123. [CrossRef]

5. Bahmani, M.A.; Thiringer, T.; Kharezy, M. Design methodology and optimization of a medium-frequency transformer for high-power DC-DC applications. IEEE Trans. Ind. Electron. 2016, 52, 4225-4233. [CrossRef]

6. Huang, P.; Mao, C.; Wang, D.; Wang, L.; Duan, Y.; Qiu, J.; Xu, G.; Cai, H. Optimal design and implementation of high-voltage high-power silicon steel core medium frequency transformer. IEEE Trans. Ind. Electron. 2017, 64, 4391-4401. [CrossRef]

7. Ozturk, S.; Canver, M.; Cadirci, I.; Ermis, M. All SiC grid-connected PV supply with HF link MPPT converter: system design methodology and development of a $20 \mathrm{kHz}, 25 \mathrm{kVA}$ prototype. Electronics 2018, 7, 85. [CrossRef]

8. Ruiz, D.; Ortíz, J.; Venegas, V.; Moreno, E.; Granados, D.; Rodríguez, J. Nanocrystalline and silicon steel medium frequency transformer applied to dc-dc converters: analysis and experimental comparison. Energies 2019, 12. [CrossRef]

9. Harischandrappa, N.; Bhat, A.K. A $10 \mathrm{~kW}$ ZVS integrated boost dual three-phase bridge DC-DC resonant converter for a linear generator-based wave-energy system: design and simulation. Electronics 2019, 8, 115. [CrossRef]

10. She, X.; Huang, Q.; Burgos, R. Review of solid-state transformer technologies and their application in power distribution system. IEEE J. Emerg. Sel. Top. Pow. Electron. 2013, 1, 186-198. [CrossRef]

11. Wang, Y.; Ni, F.; Lee, T. Hybrid modulation of bidirectional three-phase dual-active-bridge DC converters for electric vehicles. Energy 2016, 9, 492. [CrossRef]

12. Hosseinzadeh, M.; Rajaci, F. Robust optimal power management system for a hybrid AC/DC micro-grid. IEEE Trans. Sust. Energ. 2015, 6, 675-687. [CrossRef]

13. Lee, J.H.; Lee, S.H.; Sul, S.K. Variable-speed engine generator with supercapacitor: isolated power generation system and fuel efficiency. IEEE Trans. Ind. Applic. 2009, 45, 2130-2135. [CrossRef]

14. Hilzinger, R.; Rodewald, W. Magnetic Materials, 1st ed.; Publicis MCD Werbeagentur GmbH, Vaccumschmelze GmbH \& Co. KG: Hanau, Germany, 2013; pp. 280-290.

15. Sixdenier, F.; Morand, J.; Salvado, A.; Bergogne, D. Statistical study of nanocrystalline alloy cut cores from two different manufacturers. IEEE Trans. Magn. 2014, 50, 2003604. [CrossRef]

16. Chailloux, T.; Raulet, M.; Martin, C.; Joubert, C.; Sixdenier, F.; Morel, L. Magnetic behavior representation taking into account the temperature of a magnetic nanocrystalline material. IEEE Trans. Magn. 2012, 48, 455-458. [CrossRef]

17. Prochazca, R.; Hlavacek, J.; Draxler, K. Magnetic circuit of a high-voltage transformer up to $10 \mathrm{kHz}$. IEEE Trans. Magn. 2015, 51. [CrossRef]

18. Kauder, T.; Hameyer, K. Performance factor comparison of nanocrystalline, amorphous, and crystalline soft magnetic materials for medium-frequency applications. IEEE Trans. Magn. 2017, 53, 8401504. [CrossRef]

19. Roch, A.; Leferink, F. nanocrystalline core material for high-performance common mode inductors. IEEE Trans. Electromagn. Compat. 2012, 54, 785-791. [CrossRef]

20. She, X.; Yu, X. Design and demonstration of a 3.6-kV-120-V/10-kVA solid-state transformer for smart grid application. IEEE Trans. Pow. Electron. 2014, 29, 3982-3996. [CrossRef]

21. Hurley, W.; Wolfle, W. Transformer and Inductor for Power Electronics: Theory, Design and Applications; John Wiley \& Sons Ltd: West Sussex, UK, 2013; Volume 1, ISBN 9781119950578.

22. McLyman, C.W. Transformer and Inductor Design Handbook; CRC Press: New York, NY, USA, 2011.

23. Bahmani, M.A.; Thiringer, T. Accurate evaluation of leakage inductance in high frequency transformer using an improved frequency dependent expression. IEEE Trans. Pow. Electron. 2015, 30, 5738-5745. [CrossRef]

24. Hurley, W.; Wilcox, D. Calculation of leakage inductance in transformer windings. IEEE Trans. Pow. Electron. 1994, 9, 121-126. [CrossRef] 
25. Soltau, N.; Eggers, D.; Hameyer, K.; Doncker, R. Iron losses in a medium-frequency transformer operated in a high-power DC-DC converter. IEEE Trans. Magn. 2014, 50. [CrossRef]

(c)

(C) 2020 by the authors. Licensee MDPI, Basel, Switzerland. This article is an open access article distributed under the terms and conditions of the Creative Commons Attribution (CC BY) license (http://creativecommons.org/licenses/by/4.0/). 